\title{
Estimate of the Providing of Iron in Adolescents Consuming Tap Water with Increased Iron Content
}

\author{
Victor Kalinovich Koval'chuk \\ Department of Hygiene, Faculty of Public Health, Pacific State Medical University, Vladivostok, Russian Federation \\ Email address: \\ comhyg@mail.ru \\ To cite this article: \\ Victor Kalinovich Koval'chuk. Estimate of the Providing of Iron in Adolescents Consuming Tap Water with Increased Iron Content. \\ American Journal of Environmental Protection. Vol. 8, No. 1, 2019, pp. 17-21. doi: 10.11648/j.ajep.20190801.13
}

Received: December 25, 2018; Accepted: January 22, 2019; Published: February 21, 2019

\begin{abstract}
Iron contamination of drinking water in municipal water supply systems is recognized as a risk factor for impairment of public health. Tap water in the city of Vladivostok has increased iron content (more $0.8 \mathrm{mg} / 1$ ). The aim of this study was the medical assessment of the actual average daily dose (AADD) of iron consumed by Vladivostok residents with all sources its per oral administration. Present study was performed in February 2017. A random sample of 183 adolescents from 14 to 17 years old from Vladivostok municipal schools was investigated. Daily consumption of tap water, 85 trade names of bottled water, 21 groups of food products and dishes were studied by questionnaire method. The iron content in foods and drinking waters was taken according to the national reference tables and laboratory data. It was established that the iron AADD values among adolescent population were equal about $17 \mathrm{mg} / \mathrm{day}$, what is harmless to the health. At the same time the frequency of iron intake deficiency was 18.37 (boys) and 64.58 (girls) cases per 100 people. It has been found that, against the background of an excessive of the iron content in tap water (up to 2.7 MAC) according to organoleptic limiting sign of harmfulness, the occurrence of deficit of its consumption in boys and girls is due to low consumption levels of foods with the highly bioavailable iron: eggs, animal meat and poultry meat.
\end{abstract}

Keywords: Iron, Daily Intake, Tap Water, Bottled Waters, Food Products, Bioavailability, Adolescent Population

\section{Introduction}

Iron is an essential chemical element for humans [1, 2]. However, excessive iron intake can have an adverse effect on the body and cause the occurrence of diseases. [3]. One of the sources of excess iron in the body is considered to be tap water. Constant consumption of iron-contaminated drinking water can cause in a person to develop pathological changes in the skin, mucous membranes, blood and the immune system, siderosis, and deterioration of health in patients with hemochromatosis [1, 4]. Primorsky Territory should be attributed to the regions of the Russian Federation where the water of public water supply systems contains increased concentrations of iron. The excess of iron in the tap water of the territory (up to 4.1 of the maximal allowable concentration (MAC)) is formed by the high corrosive activity of soft, low-mineralized water and geochemical features of underground sources $[5,6]$. The contamination of drinking water with iron is the main cause of numerous complaints and lawsuits of the region population to the owners of drinking water supply systems. Against this background, it is necessary to recognize as paradoxical the fact of the presence of chronic iron deficiency in the body of children, revealed during the in-depth medical examination of organized children's groups in Primorsky Territory [7]. The causes of this phenomenon have not been studied.

The article presents the results of a study carried out for the purpose of medical evaluation of the actual average daily dose (AADD) of iron consumed by adolescent population with traditional sources of its oral intake under conditions of excessive iron in drinking water.

\section{Materials and Methods}

\subsection{District and Object of Observation}

The study was performed in Vladivostok in February 2017. In this city, iron pollution of tap water that comes from three surface sources is up to 2.7 times the MAC, and the population has the highest level of per capita monthly income 
in the region $[6,8]$, that is, residents of Vladivostok have the highest levels of food consumption, including iron rich. The object of observation was the adolescent population of 14-17 years. At this age, children have a second peak in the iron consumption growth associated with physiological restructuring and development of the body $[2,9] .183$ pupils from 16 high schools in the city were covered by the onetime (transverse) selective study. The random nature of the sample was provided by the selection of the required number of persons for the study using a random number generator from the previously drawn up a pass-through list of last classes pupils at these schools with assignment of conditional number to each person. The minimum sample size was calculated by the generally accepted method with a confidence probability of $p=0.95$ and a confidence factor of $t=1.96$.

\subsection{Determination of Daily Iron Intake and Calorie of Diet}

The iron content in the average daily diet was studied by analyzing the frequency of food intake [10]. The questionnaire for the survey of schoolchildren, in addition to questions about the consumption of 21 names of food and dishes, contained items on the consumption of tap water, bottled table water (42 trade names) and medical-table water (43 trade names). The indicator of the energy value of the daily diet was used for identification of non-objectively completed questionnaires. The calorie values of the ration below the amount of basal metabolism in the body (boys $1330 \mathrm{kcal}$, girls $-1322 \mathrm{kcal}$ ) and above $130 \%$ of the recommended consumption in the Russian Federation (boys $-3770 \mathrm{kcal}$, girls $-3250 \mathrm{kcal}$ ) were the criteria for rejection of questionnaires.

\subsection{Calculation of the Actual Average Daily Dose (AADD) of Intake of Iron}

The average daily dose (ADD) of iron intake with selected foods and bottled waters and the caloric content of the diet was calculated using the chemical composition tables [11, 12], tap water - according to previous research [5]. In doing so ADD of iron intake for a selected type of water was calculated by the standard formula [12] modified by author of this article to work with biogenic elements, and month period of observation:

$$
\mathrm{ADD}=\mathrm{C}_{\mathrm{w}} \times \mathrm{V} \times \mathrm{EF} / 31,
$$

Where;

$C_{w}=$ the concentration of the element in water, $\mathrm{mg} / \mathrm{l}$
$V=$ the average volume of water consumption, $1 /$ day

$E F=$ frequency of water consumption, days/month.

The value of the actual total average daily dose (AADD) of iron intake was calculated by summing ADD of the intake with selected foods and drinking waters.

\subsection{Statistical Analysis}

For a statistical study of the obtained data, the application package Statistica 10.0 for Windows and a specialized program for calculating the weight of the ranked factors in the feature variability [13] were used. The distribution estimate was performed using Pearson $\chi^{2}$ test. The results of the analysis for the normal distribution were presented as an arithmetic mean and 95\% confidence interval, for other distributions - as a median and interquartile range (25 and 75 percentiles). Significance of differences of average values for a normal distribution was evaluated by the Student's $t$ test for independent samples, and for asymmetric distributions - by the Kolmogorov-Smirnov's test $\lambda$.

To calculate the degree of influence of each food product on variability in AADD of iron intake, multiple linear regression analysis of the ranked values was used [13]. In so doing AADD value was taken as the dependent variable, and ADD values of separate sources of iron consumption were taken as independent variables. A direct algorithm for the inclusion of independent variables was implemented in the regression analysis. An algorithm for equations of the linear form was used in calculating the confidence interval for the regression coefficients [14].

\section{Results and Discussion}

\subsection{Estimation of the Actual Average Daily Dose}

The AADD values of iron intake by the adolescent population are given in table 1 . In general, the daily consumption of iron by adolescents in the city of Vladivostok practically corresponds to the average Russian iron consumption value - $17.0 \mathrm{mg} /$ day [15]. It has been established that boys receive a sufficient dose of iron (19.14 $\mathrm{mg} /$ day, the recommended value of intake is $15.0 \mathrm{mg} /$ day), and girls have a shortage of its intake $(15.13 \mathrm{mg} /$ day, the recommended value of intake is $18.0 \mathrm{mg}$ /day), despite a higher physiological need for iron. At the same time should be emphasized the usefulness of culling some results of the questioning, because at that age girls are inclined to understate and boys overstate the levels of food consumption.

Table 1. The investigation results of iron intake with food and drinking waters in the adolescent population.

\begin{tabular}{lllll}
\hline Group of population & $\begin{array}{l}\text { All investigated } \\
\text { persons }\end{array}$ & $\begin{array}{l}\text { Rejection } \\
\text { More than the upper } \\
\text { limit selection }\end{array}$ & $\begin{array}{l}\text { Rejection } \\
\text { Less than the lower } \\
\text { limit of selection }\end{array}$ & $\begin{array}{l}\text { Taken into analysis } \\
\text { AADD/day } \mathbf{M} \text { (95\% CI) }\end{array}$ \\
\hline Boys & 85 & 13 & 23 & 49 \\
Girls & 98 & 6 & 44 & 48 \\
\hline
\end{tabular}

Abbreviations: M, arithmetical mean; CI, confidence interval of the arithmetical mean at $\mathrm{p}$.

The values of recommended iron intake for this age group [15], as well as $90 \%$ of these values were used to analyze the 
distribution of various AADD values of iron intake with food and drinking waters among the adolescent population of the city. This approach is more appropriate for the assessment of individual intake values when using standards that are group-based [10, 15]. It was revealed that the deficiency of iron consumption was significantly more than 3 times more often $\left(p=3.86^{-7} ; 1.03^{-6} ; 3.86^{-7}\right)$ among girls than among boys (Table 2). At the same time, the frequency of occurrence of iron deficiency among boys (18.37 per 100 people) is below the average value of the prevalence of this deficit among schoolchildren in Russia (30.0 per 100 people) [2], and among girls it is much higher (64.58 per 100 people.). In other words, the high level of iron contamination of tap water in the city does not reduce the prevalence of deficiency of consumption of this element in the population, as the criterion for assessing the pollution of drinking water (MAC) for iron in the Russian Federation is based on change in the organoleptic properties of water, and not on the manifestation of toxicity to the human body.

Table 2. The distribution of AADD values of iron intake from food and drinking waters among the adolescent population (cases per 100 people).

\begin{tabular}{|c|c|c|c|c|c|}
\hline AADD value & $\begin{array}{l}\text { Boys }(n=49) \\
\text { Absolute number }\end{array}$ & $\begin{array}{l}\text { Boys } \\
P_{1}(95 \% \text { CI }) \\
\end{array}$ & $\begin{array}{l}\text { Girls }(n=48) \\
\text { Absolute number }\end{array}$ & $\begin{array}{l}\text { Girls } \\
P_{2}(95 \% \text { CI }) \\
\end{array}$ & $\mathbf{P}_{1}-\mathbf{P}_{2}$ \\
\hline Less than recommended intake: total & 12 & $24.49(12.45 ; 36.53)$ & 35 & $72.92(60.35 ; 85.49)$ & $\mathrm{p}<0.001$ \\
\hline $\begin{array}{l}\text { Less than recommended intake: of these, less } \\
\text { than } 90 \% \text { of the recommended value }\end{array}$ & 9 & $18.37(7.53 ; 29.21)$ & 31 & $64.58(51.05 ; 78.11)$ & $\mathrm{p}<0.001$ \\
\hline More than recommended intake & 37 & $75.51(63.47 ; 87.55)$ & 13 & $27.08(14.51 ; 39.65)$ & $\mathrm{p}<0.001$ \\
\hline
\end{tabular}

It is known that the level of iron content in the body is influenced not only by the AADD value of its consumption, but also by the degree of bioavailability of this element in foods and drinking waters $[2,3,16]$. In this study, consideration of the bioavailability factor was made on the basis of scientific literature. The published data, divided into two groups - "low bioavailability" and "high bioavailability", are summarized in table 3 . The first group includes sources in which, despite the high content of total iron, dominate difficult to digestible chelate iron complexes (plant products) or its humates, sulphates, hydroxides and others (tap water). The second group of sources is represented mainly by high bioavailability compounds of trivalent heme iron (meat and fish products) and ferrous iron (mineral water) [2, 17-24]. However, unlike food products, bivalent iron compounds in groundwater are unstable and, in the presence of atmospheric oxygen, quickly turn into iron oxide with low bioavailability.

Table 3. The main iron-containing compounds in traditional sources of iron intake into the body [2, 17-24].

\begin{tabular}{|c|c|c|}
\hline Sources of intake & Low bioavailability (1-12\%) & High bioavailability (20-33\%) \\
\hline Animal meat, poultry meat, sausages, eggs (egg white) & - & Heme \\
\hline Fish & - & Ferritin, hemosiderin, heme \\
\hline Bread, pasta, cereal porridges & Iron phosphates, iron ferrous phytate & - \\
\hline Potatoes, cabbage, vegetable salads, fruits & Iron chelates with dietary fibers, phytates and tannins & - \\
\hline Confectionery & Iron chelates with phytates and tannins & - \\
\hline $\begin{array}{l}\text { Drinking water from underground sources (mineral, } \\
\text { tap, well) }\end{array}$ & $\mathrm{FeHCO}_{3}, \mathrm{FeCl}_{2}, \mathrm{Fe}_{2}\left(\mathrm{SO}_{4}\right)_{3}$ & $\mathrm{FeO}, \mathrm{FeSO}_{4}$ \\
\hline
\end{tabular}

The study of the AADD structure of iron intake with regard to its bioavailability has revealed no significant differences between the sexes of adolescents. Taking into consideration the asymmetric distribution of the values of AAD consumption with individual foods, the nonparametric criterion $\lambda$ was used for the analysis. All differences between boys and girls in value of $\lambda$ did not reach statistical significance. The main feature of the structure of iron consumption is the predominance of low bioavailable compounds of plant origin $(52.75 \%)$, water origin $(9.97 \%)$ and animal origin $(2.75 \%)$. The proportion of sources of high bioavailable iron accounts for only $34.53 \%$. Taking into account the small AADD values of total iron (Table 1), the low proportion of intake of high bioavailable iron may cause latent iron deficiency in the children population of the region, despite excessive iron content in tap water in accord the organoleptic sign of harm.

\subsection{Assessment of the Degree of Influence of the Individual Sources of Consumption on the Amount of Actual Average Daily Dose}

The population-level research makes it possible to measure the degree of influence of the variability of consumption of the individual source of iron among the population on the variability of its statistical average AADD. The analysis did not include the consumption of the ferrous carbonic medical table waters - source high availability of ferrous iron. Their proportion in AADD structure was less than $0.3 \%$. The results of the analysis are presented in Table 4. 
Table 4. The results of the analysis of the degree of influence of foods from the group of highly bioavailable iron sources on the AADD value of total iron intake in adolescent population.

\begin{tabular}{|c|c|c|c|c|c|c|}
\hline Food product & $\begin{array}{l}\text { Boys } \\
\text { A }(95 \% \text { CI })\end{array}$ & $\begin{array}{l}\text { Boys }\left(\mathrm{R}^{2}=0.35\right) \\
\text { B }(95 \% \mathrm{CI})\end{array}$ & $\begin{array}{l}\text { Boys } \\
\text { P }\end{array}$ & $\begin{array}{l}\text { Girls } \\
\text { A }(95 \% \text { CI })\end{array}$ & $\begin{array}{l}\text { Girls }\left(R^{2}=0.44\right) \\
\text { B }(95 \% C I)\end{array}$ & $\begin{array}{l}\text { Girls } \\
\text { P }\end{array}$ \\
\hline Animal meat & $1.27(0.96 ; 1.58)$ & $0.44(0.24 ; 0.64)$ & $21.0 \%$ & $0.47(-0.16 ; 1.10)$ & $0.50(0.31 ; 0.69)$ & $29.0 \%$ \\
\hline Sausages & $2.86(2.17 ; 3.55)$ & $0.22(0.12 ; 0.32)$ & $10.8 \%$ & $1.66(-0.58 ; 3.70)$ & $0.03(0.02 ; 0.04)$ & $2.3 \%$ \\
\hline Fish & $1.61(1.22 ; 2.00)$ & $-0.66(-0.09 ;-0.03)$ & $4.0 \%$ & $-56268.00(-132168.00 ; 19632.00)$ & $-0.03(-0.04 ;-0.02)$ & $0.7 \%$ \\
\hline Poultry meat & $1.88(1.43 ; 2.33)$ & $0.25(0.14 ; 0.36)$ & $14.0 \%$ & $0.06(-0.02 ; 0.14)$ & $0.27(0.17 ; 0.37)$ & $14.5 \%$ \\
\hline Eggs & $1.48(1.12 ; 1.84)$ & $0.13(0.07 ; 0.19)$ & $\begin{array}{l}50.2 \% \\
\text { Total: } 100 \%\end{array}$ & $0.31(-0.11 ; 0.73)$ & $0.10(0.06 ; 0.14)$ & $\begin{array}{l}53.5 \% \\
\text { Total: } 100 \%\end{array}$ \\
\hline
\end{tabular}

Abbreviations: $\mathrm{P}$ - degree of influence;

A - unadjusted regression coefficient;

$\mathrm{B}$ - adjusted regression coefficient;

$\mathrm{CI}-$ confidence interval of the regression coefficient at $\mathrm{p}<0.05$;

$\mathrm{R}^{2}$ - theoretical index of determination.

The values of the unadjusted and adjusted regression coefficients in the table confirm the expediency of using the ranked (adjusted) values of variables in the multiple regression analysis. This approach allowed to reduce the distortion of results when working with asymmetric distributions. It has been established that among boys the consumption of eggs $(50.2 \%)$, animal meat $(21 \%)$ and poultry meat $(14 \%)$ have the greatest influence on AADD of total iron among sources of high bioavailable iron. The girls also showed similar results: consumption of eggs - $53.5 \%$, consumption of animal meat - $29 \%$, consumption of poultry meat $-14.5 \%$.

\subsection{Discussion}

A review of the results of the study made it possible to state that the constant consumption of iron-contaminated tap water from surface sources does not form an excess intake of total iron in the adolescent population. This is confirmed by the average AADD values (boys - $19.14 \mathrm{mg}$ /day, girls - 15.13 $\mathrm{mg} /$ day). In the city studied, against the background of using tap water with an iron content of up to $0.8 \mathrm{mg} / \mathrm{l}$ (2.7 of MAC) and the maximum level of foods consumption in the region [8], they almost correspond to the average value of iron intake in Russia - $17.0 \mathrm{mg}$ /days [15]. This conclusion is consistent with the results were obtained earlier in Vladivostok during a pilot study in 2013. In that year, the AADD of iron consumption in boys was 17.69 (95\% CI: 15.79 - 19.60) $\mathrm{mg} /$ day, in girls - 16.55 (95\% CI: 14.73 $18.38) \mathrm{mg} /$ day [25].

Identified values of AADD of oral iron intake also cannot be considered harmful to the health of adolescents, since they make up only $127.6 \%$ (boys) and $84 \%$ (women) of the recommended value of consumption in Russia [15] and do not exceed the value of "tolerable upper intake level" for oral consuming in adolescence $-45 \mathrm{mg}$ /day adopted by the World Health Organization [3]. However, the results of presented study do not exclude the harmful effects of ironcontaminated tap water on adolescents when it contacts with the skin.

The high prevalence of adolescents with iron deficiency (Table 2) confirms data on the presence of latent iron deficiency in younger children which live in this region [7].
This deficiency is formed by the nutritional factor, primarily the lack or the absence such sources of high bioavailable iron as eggs and meat of animals and birds in the daily ration, the leading role of which is indicated by the results of regression analysis (Table 4). These sources of iron consumption are a priority for both boys and girl. Unlike the observations in 2013 [25], the present study did not reveal any gender differences in food products, the lack of which forms the iron deficiency in the body in maximum extent. It is established that eggs have a greatest effect on iron intake (more than $53 \%)$. The high efficiency of eggs in providing humans with high bioavailable iron and in preventing iron deficiency states has been identified in experimental studies. The main supplier of iron in eggs and the regulator of the process of its assimilation in a living organism is egg white [26].

The iron consumed by residents with drinking water from surface water bodies in the area of observation cannot influence this process, since it is fully represented by low bioavailable iron oxide compounds (Table 3). These data should be considered when developing a regional program for the prevention of iron deficiency among the population.

The revealed predominance of iron consumption deficit among girls cannot be recognized as a regional feature, it reflects a general pattern in most countries of the world $[2,9$, 18-22]. Adolescent girls have high risk of the delayed development, the occurrence of hypochromic anemia, fatigue, atrophic gastritis, myocardiopathy [15, 27].

\section{Conclusion}

The presented study showed that living in the region with excess iron content in drinking water (up to $2.7 \mathrm{MAC}$ ), according to the organoleptic limiting sign of harmfulness, does not form unfavorable for health AADD values of iron oral intake in the adolescent population. However, against the background of the consumption of iron-contaminated tap water there is a high incidence of insufficient iron consumption among the adolescent population, especially among girls (64.58 per 100 people), whose body is most sensitive to iron deficiency. The most productive measure for the prevention of latent iron deficiency in girls and boys in the studied region of Russia is an increase in the consumption 
of eggs, as well as animal and poultry meat.

\section{Acknowledgements}

The author of the article expresses his sincere appreciation to the doctor of biological sciences, professor Vladimir Koldaev, the employee of the Federal Scientific Center of the East Asia Terrestrial Biodiversity Far Eastern Branch of the Russian Academy of Sciences for his methodological assistance in statistical analysis of the data from the adolescent population survey and moral support in carrying out this research.

\section{References}

[1] Agadzhanyan N. A., Veldanova M. V. and A. V. Skal'nyi, 2001. Environmental portrait of a man and the role of trace elements. Moscow, 236p. [in Russian]

[2] Uvarova E. V., Grigorenko U. P. and N. V. Sergeeva, 2008. Prevalence and possibilities of eliminating iron deficiency anemia in girls with various gynecological pathologies. Reproductive Health of Children and Adolescents 5; 43-52. [in Russian]

[3] Olivares M. and R. Uauy, 2005. Essential nutrients in drinking water. In: Nutrients in drinking water. Geneva: WHO, p.41-60.

[4] Onischenko G. G., Novikov S. M., Rahmanin U. A., Avaliani S. L. and K. A. Bushtueva, 2002. Basics of risk assessment to public health when exposed to chemicals that pollute the environment. Moscow, NII ECh i GOS, 2002, 408p. [in Russian].

[5] Koval'chuk V. K. and D. V. Maslov, 2006. Hygienic problems of the chemical composition of drinking water of water supply systems of Primorsky Territory. Pacific Medical Journal. 3; 6063. [in Russian].

[6] Problems of providing the population of Primorsky Territory with drinking water and ways to solve them: Regional target program "Providing the population of Primorsky Territory with drinking water". 2000. Vladivostok, Dalnauka, 389p. [in Russian].

[7] Trankovskaya L. V. and V. N. Luchaninova, 2006. Prevalence, risk factors and prediction of mineral imbalances in children. Pacific Medical Journal 2; 22-25. [in Russian].

[8] Koval'chuk V. K., Ivanova I. L. and V. M. Koldaev, 2011. The role of the environment in the occurrence of non-communicable diseases of the digestive system in the Primorsky Territory. Hygiene and sanitary 3; 10-15. [in Russian].

[9] Broniecka A., Wyka J., Bronkowska M., Piotrowska E. and J. Biernat, 2014. Assessment of intake of iron and nutrients that affect bioavailability of daily food rations of girls. Annals of Agricultural and Environmental Medicine. 2; 327-330.

[10] Martinchik A. N., Maev I. V. and O. O. Yanushevich, 2005. General Nutrition. Moscow, MEDpress-inform, 392p. [in Russian].

[11] Tutelyan V. A., 2012. Chemical composition and caloric content of Russian foods: Handbook. Moscow: DeLi Plus, 284p. [in Russian].
[12] Mineral waters of the Far East: Handbook /Ed. by B. I. Chelnokova, 2006. Vladivostok, Publishing house of the Far Eastern University, 107p. [in Russian].

[13] Koldaev V. M., Koval'chuk V. K. and I. L. Ivanova, 2010. The weight of ranked features in the variability of feature. Programs for computer RU OBPBT 3; 298. [in Russian].

[14] Myatlev V. D., Panchenko L. A., Riznichenko G. Yu and A. T. Terehin, 2009. Probability theory and mathematical statistics. Mathematical models. Moscow, Press center «Akademiya», 320p. [in Russian].

[15] MR 2.3.1.2432-08., 2008. The norms of physiological needs for energy and nutrients for different groups of the population of the Russian Federation. Moscow, Federal Center of Hygiene and Epidemiology of Rospotrebnadzor, 41p. [in Russian].

[16] La Frano M. R., de Moura F. F., Boy E. and B. J. Burri, 2014 Bioavailability of iron, zinc, and provitamin A carotenoids in biofortified staple crops. Nutrition Reviews. 5; P. 289-307.

[17] Mazaev V. T., Ilnickiy A. P. and T. G. Shlepnina, 2008. Guidance on hygiene of drinking water and drinking water supply. Moscow, OOO «Medical information agency», 320p. [in Russian].

[18] Chiploncar S. A., Tarwadi K. V., Kavedia R. B., Mengale S. S., Paknikar K. M. and V. V. Agte, 1999. Fortification of vegetarian diets for increasing bioavailability iron density using green leafy vegetables. Food Research International 3; 169-174.

[19] House W. A., 1999. Trace element bioavailability as exemplified by iron and zinc. Field Crops Research 1-2; 115-141.

[20] Kumari M., Gupta S., Lakshmi A. J. and J. Prakash, 2004. Iron bioavailability in green leafy vegetables cooked in different utensils. Food Chemistry 2; 217-222.

[21] Khouzam,R. B., Pohl P. and R. Lobinski, 2011. Bioaccessibility of essential elements from white cheese, bread, fruit and vegetables. Talanta $86 ;$ 425-428.

[22] Bonsmann S. S. G., Walczyk T., Renggli S. and R. F. Hurrell, 2008. Oxalic acid does not influence nonohaem iron absorbtion in humans: a comparison of kale and spinach meals. European Journal of Clinical Nutrition 3; 336-341.

[23] Raghuvanshi R. S., Singh R. and R Singh, 2001. Nutritional composition of uncommon foods and their role in meeting micronutrient needs. International Journal of Food Science and Nutrition 4; 331-335.

[24] Gibson R. S., Raboy V. and J. C. King, 2018. Implications of phytate in plant-based foods for iron and zinc bioavailability, setting dietary requirements, and formulating programs and policies. Nutrition Reviews. 1; P. 793-804.

[25] Kova'lchuk V. K., 2015. Estimation of actual iron consumption by adolescent population in region with high content of iron in drinking water. Human Ecology 5; 8-13. [in Russian].

[26] Kobayashi Y., Wakasugi E., Yasui R. Kuwahata M. and Y. Kido, 2015. Egg yolk protein delays recovery while ovalbumin is useful in recovery from iron deficiency anemia. Nutrients 7; 4792-4803.

[27] Camaschella C. I., 2019. Iron deficiency. Blood. 1. P. 30-39. 